\title{
EFEK MINYAK ESENSIAL LAVENDER DIBANDINGKAN DENGAN MINYAK ESENSIAL JAHE TERHADAP INTENSITAS NYERI MENSTRUASI PADA REMAJA
}

\author{
Wasis Pujiati ${ }^{1}$, Mae Sri Hartati $\mathbf{W}^{2}$, Elsi Dwi Hapsari ${ }^{3}$
}

\begin{abstract}
Background: Menstrual pain is the pain in the abdomen which is perceived before or during menstruation, that even when the menstrual pain is heavily painful, the sufferers leave their activities. Research in 2011 showed that the rate of occurrence of primary menstrual pain in Indonesian adolescences was about $54.89 \%$. Various therapies have been used to cure the pain, both pharmacologically and nonpharmacologically. Pharmacologically, it is done by the usage of NSAID, and non-pharmacologically is done by using essential oil.
\end{abstract}

Objective: To know about the effects of lavender essential oil compared to ginger essential oil toward the intensity of menstrual pain in the adolescences of SHS 1 Muncar.

Method: True experimental design, with randomized pretest posttest design plan. Time of data retrieval was August-September 2014 in SMA 1 Muncar, Banyuwangi, East Java. Population in this research were female adolescences in class of $X$ and XI, with the amount of 260 students, with samples' amount of 30 for each treatment group. The sampling technique was simple random sampling. The dependent variable are the giving of lavender and ginger essential oils, meanwhile the independent variable are the reduction of the intensity of menstrual pain. Instrument which was used was Numerical Rating Scale. The data analysis used the Wilcoxon and Mann-Whitney Test.

Result and Discussion: The intensity of pain before and after intervention of essential oil of lavender and ginger are $5,47 \pm 1,19$ vs $2,93 \pm 1,53, P=0,00$ and $5,40 \pm 0,96$ vs $2,93 \pm 1,43, P=0,00$, respectively. Comparison of the effects essential oil of lavender and ginger have $P>0,05$.

Conclusion: Both lavender essential oil and ginger essential oil are effective in reducing the intensity of menstrual pain in adolescences.

Keywords: Menstrual pain, Essential oils, Lavender, Ginger, Adolescences

\begin{abstract}
ABSTRAK
Latar Belakang: Nyeri menstruasi merupakan nyeri pada abdomen yang dirasakan sebelum maupun selama menstruasi, bahkan pada saat mengalami nyeri menstruasi yang berat penderita sampai meninggalkan aktivitasnya. Penelitian pada tahun 2011, menunjukan angka kejadian nyeri menstruasi primer pada remaja di Indonesia sekitar 54,89\%. Berbagai terapi telah digunakan untuk mengobati nyeri baik secara farmakologi maupun non farmakologi. Secara farmakologi dengan penggunaan NSAID (Non Steroidal Anti-inflammatory Drugs), secara non farmakologi salah satunya dengan menggunakan minyak esensial.

Tujuan: Untuk mengetahui efek antara minyak esensial lavender dibandingkan dengan minyak esensial jahe terhadap intensitas nyeri menstruasi pada remaja di SMAN I Muncar.
\end{abstract}

\footnotetext{
Magister Keperawatan UGM (Dosen Stikes Hangtuah Tanjungpinang)

Bagian Farmakologi dan Terapi UGM

Bagian Keperawatan UGM
} 
Metode: Desain true experimental, rancangan randomized pretest posttest design. Waktu pengambilan data Agustus-September 2014 di SMAN I Muncar, Banyuwangi, Jawa-Timur. Populasi dalam penelitian ini adalah remaja perempuan kelas X dan XI sejumlah 260 siswa, sampel sejumlah 30 untuk masingmasing kelompok perlakuan. Teknik sampling dengan simple random sampling. Variabel dependen yaitu pemberian minyak esensial lavender dan jahe, variabel independen yaitu penurunan intensitas nyeri menstruasi. Instrumen yang digunakan Numerical Rating Scale. Analisa data menggunakan Uji Wilcoxon dan Mann Withney.

Hasil dan Pembahasan: Intensitas nyeri sebelum dan sesudah intervensi pada kelompok lavender dan jahe masing-masing adalah $5,47 \pm 1,19$ vs $2,93 \pm 1,53, P=0,00$ dan $5,40 \pm 0,96$ vs $2,93 \pm 1,43, P=0,00$. Perbandingan efek minyak esensial lavender dan jahe dengan nilai $P>0,05$

Kesimpulan: Minyak esensial lavender dan minyak esensial jahe sama-sama efektif dalam menurunkan intensitas nyeri menstruasi pada remaja.

Kata Kunci Nyeri menstruasi, Minyak esensial, Lavender, Jahe, Rem

\section{PENDAHULUAN}

Nyeri menstruasi merupakan nyeri pada abdomen yang dirasakan sebelum maupun selama menstruasi, bahkan pada saat mengalami nyeri menstruasi yang berat penderita sampai meninggalkan aktivitasnya. ${ }^{1} \quad$ Nyeri menstruasi berkaitan dengan kram pada perut bagian bawah dan nyeri punggung, disertai mual, muntah, kelelahan, kecemasan, sakit kepala, emosi yang labil, kecemasan, depresi dan diare. ${ }^{2}$

Perkiraan angka kejadian nyeri menstruasi pada remaja $20 \%-90 \%$. Sekitar $15 \%$ pada remaja melaporkan nyeri menstruasi berat. Nyeri saat menstruasi dilaporkan sebagai keluhan ginekologis paling umum dan paling sering menyebabkan absennya seorang remaja ataupun dewasa dari sekolah, kerja, olahraga ataupun aktivitas yang lain. ${ }^{3,4}$ Angka kejadian nyeri menstruasi yang tinggi menjadi alasan untuk tidak masuk sekolah atau kampus, sedikit yang mencari pengobatan dan hanya berobat secara mandiri. ${ }^{5}$ Tahun 2010 hasil penelitian di China menunjukkan sekitar $41,9 \%-79,4 \%$ remaja mengalami Nyeri menstruasi primer dengan rincian 31,5\%-41,9\% terjadi pada usia 9-13 tahun dan $57,1 \%-79,4 \%$ terjadi pada usia 14 -
18 tahun. $^{6}$ Penelitian tahun 2011 menunjukkan angka kejadian nyeri menstruasi primer pada remaja di Indonesia sekitar 54, 89\%. ${ }^{7}$

Berbagai terapi telah digunakan untuk mengobati nyeri baik secara farmakologi maupun non farmakologi. Secara farmakologi obat-obatan antiinflamasi golongan non steroid seperti ibuprofen, naproksen, asam mefenamat dan aspirin banyak digunakan sebagai terapi awal untuk nyeri menstruasi. ${ }^{8,2,9}$ Obat tersebut akan menimbulkan efek samping jika digunakan secara berulang tanpa pengawasan dokter. Mengingat efek samping yang dapat ditimbulkan oleh penggunaan NSAID, maka diperlukan alternatif lain untuk mengatasi dan mengurangi rasa nyeri yaitu dengan menggunakan bahan alami.

Aromaterapi merupakan tindakan keperawatan komplementer. Berbagai jenis minyak esensial digunakan untuk aromaterapi, seperti melissa, eucalyptus dan lavender. Minyak tersebut bersifat rileksasi, mengurangi nyeri, stres, dan meningkatkan kesehatan. Lavender sebagai minyak esensial mempunyai beberapa manfaat yaitu mengurangi nyeri, antidepresan, antimikrobial. ${ }^{10,11}$ Jahe merupakan obat herbal yang aman dan tidak menimbulkan efek 
samping yang merugikan. Komponen seperti gingerol, shogaol dan zingerone memberi efek farmakologi dan fisiologi seperti antioksidan, antiinflamasi yaitu menghambat prostaglandin dengan cara menghambat enzim siklooksigenase dan lipoksigenase. Hal itu akan mengakibatkan penurunan leukotrien dan prostaglandin yang merupakan mediator radang. Efek tersebut sama dengan efek antiradang dari asam mefenamat dan ibuprofen yang merupakan golongan NSAID. ${ }^{12}$ Hasil penelitian dengan menggunakan minyak lavender untuk kelompok intervensi menunjukkan bahwa nyeri menstruasi menurun dari $82,38 \%$ menjadi $51,13 \%$ setelah pijat aromaterapi. ${ }^{13}$

Penelitian yang dilakukan pada kelompok perlakuan diberikan campuran beberapa minyak antara lain clary sage, marjoram, kayu manis, jahe dan geranium menunjukkan hasil bahwa penurunan nyeri menstruasi secara signifikan lebih tinggi pada kelompok perlakuan dibandingkan kelompok acetaminophen. ${ }^{14}$ Berdasarkan penelitian di atas minyak esensial lavender maupun minyak esensial jahe digunakan untuk penurunan nyeri menstruasi tetapi minyak esensial jahe penggunaannya dikombinasikan dengan minyak esensial yang lain. Penelitian yang akan dilakukan peneliti dengan menggunakan minyak esensial jahe tanpa dikombinasikan dengan jenis minyak esensial yang lain. Berdasarkan studi pendahuluan dengan wawancara terhadap 20 remaja putri didapatkan 7 orang mengatakan mengalami nyeri pada saat menstruasi, dan belum pernah dilakukan penelitian untuk menurunkan nyeri menstruasi pada remaja perempuan di SMAN I Muncar, Banyuwangi. Berdasarkan latar belakang yang telah dikemukakan di atas peneliti tertarik untuk membandingkan efek dari kedua minyak tersebut dalam mengurangi nyeri menstruasi (dengan menggunakan minyak esensial lavender atau minyak esensial jahe dengan teknik pengolesan.

\section{METODE}

Jenis Penelitian ini menggunakan desain true eksperimental dengan rancangan randomized pretest posttest design, yaitu membandingkan subjek sebelum dan sesudah diberikan minyak esensial lavender dan subjek yang diberikan minyak esensial jahe dalam penurunan intensitas nyeri menstruasi.

Populasi dan sampel penelitian adalah siswi SMAN I Muncar dengan 260 siswi, dan kelompok perlakuan 30 untuk masing-masing kelompok. Pemilihan sampel berdasarkan kriteria inklusi dan ekslusi. Siswi akan di ukur intensitas nyerinya, apabila memenuhi kriteria dan bersedia menjadi responden dalam penelitian akan diberikan minyak esensial dan dijelaskan tata cara penggunaannya. b) penentuan kelompok minyak lavender atau jahe menggunakan simple random sampling. Alat ukur yang digunakan untuk mengukur nyeri menggunakan Numeric Rating Scala. Data dianalisis menggunakan Uji Wilcoxon dan Mann Withney dengan tingkat kemaknaan $\alpha=0,05$.

\section{HASIL DAN PEMBAHASAN}

\section{Skrining Nyeri Menstruasi}

Responden pada penelitian ini adalah siswi SMAN I Muncar yang berjumlah 60 siswi yang diperoleh setelah dilakukan skrining terhadap kelas X dan kelas XI yang berjumlah 260 siswi. Masing-masing terapi diberikan pada 30 siswi. 
a. Karakteristik Kelompok Perlakuan I (Kelompok Lavender) dan Kelompok Perlakuan II (Kelompok Jahe).

Tabel 1. Karakteristik Responden Berdasarkan Umur, Usia menarche, Berat Badan, Tinggi Badan dan Body Mass Index

\begin{tabular}{|c|c|c|c|c|c|}
\hline \multirow[t]{2}{*}{ Karakteristik } & \multicolumn{2}{|c|}{$\begin{array}{l}\text { Kelompok Lavender } \\
\qquad \mathrm{n}=30\end{array}$} & \multicolumn{2}{|c|}{$\begin{array}{l}\text { Kelompok Jahe } \\
\qquad \mathrm{n}=30\end{array}$} & \multirow[t]{2}{*}{$p$ value } \\
\hline & $\%$ & Mean $\pm S D$ & $\%$ & Mean $\pm S D$ & \\
\hline Umur (tahun) & & $15,27 \pm 0,45$ & & $15,50 \pm 0,57$ & 0,09 \\
\hline 15 & 73,3 & & 53,3 & & \\
\hline 16 & 26,7 & & 43,3 & & \\
\hline 17 & 0 & & 3,33 & & \\
\hline $\begin{array}{l}\text { Usia menarche } \\
\text { (tahun) }\end{array}$ & & $12,87 \pm 0,97$ & & $12,63 \pm 1,18$ & 0,40 \\
\hline BB (kg) & & $42,20 \pm 6,6$ & & $43,60 \pm 5,87$ & 0,38 \\
\hline $\mathrm{TB}(\mathrm{cm})$ & & $149,07 \pm 6,6$ & & $154,3 \pm 6,74$ & 0,27 \\
\hline
\end{tabular}

Berdasarkan tabel 2 dilihat dari $\mathrm{p}$ value kelompok jahe pada aspek umur, usia menarche, bahwa tidak ada perbedaan karakteristik yang body mass index, berat badan dan tinggi badan. signifikan pada kelompok lavender maupun

b. Intensitas nyeri sebelum dan sesudah diberikan minyak esensial lavender

Tabel 2. Intensitas nyeri sebelum dan sesudah diberikan minyak esensial lavender

\begin{tabular}{llll}
\hline & Intensitas nyeri & & \\
\hline Perlakuan & Mean \pm SD & Rentang & $P$ value \\
\hline Sebelum & $5,47 \pm 1,19$ & $4,00-9,00$ & 0,00 \\
Sesudah & $2,93 \pm 1,53$ & $0,00-7,00$ & \\
\hline
\end{tabular}

Berdasarkan tabel 3 menggunakan uji intensitas nyeri sebelum diberikan minyak statistik wilcoxon didapatkan $\mathrm{p}=00$ artinya ada esensial lavender dan sesudah diberikan minyak perbedaan yang signifikan dalam penurunan esensial lavender. 


\section{c. Intensitas nyeri sebelum dan sesudah diberikan minyak esensial jahe}

Tabel 3. Intensitas nyeri sebelum dan sesudah diberikan minyak esensial jahe

\begin{tabular}{llll}
\hline \multicolumn{5}{c}{ Intensitas nyeri } & & \\
\hline Perlakuan & Mean \pm SD & Rentang & Pvalue \\
\hline Sebelum & $5,40 \pm 0,968$ & $4,00-8,00$ & 0,00 \\
Sesudah & $2,93 \pm 1,43$ & $0,00-6,00$ & \\
\hline
\end{tabular}

Berdasarkan tabel 4 menggunakan uji statistik wilcoxon didapatkan $\mathrm{p}=000$ artinya ada perbedaan yang signifikan dalam penurunan

\section{d. Perbandingan efek minyak esensial lavender dibandingkan dengan minyak esensial jahe}

Tabel 4. Perbandingan efek minyak esensial lavender dibandingkan dengan minyak esensial jahe

\begin{tabular}{lcc}
\hline Perlakuan & \multicolumn{2}{c}{$\mathrm{n}=30$} \\
& Mean ranks & P value \\
\hline Lavender & 30,22 & 0,897 \\
Jahe & 30,78 & \\
\hline
\end{tabular}

Berdasarkan tabel 4 menggunakan Uji Mann Whitney bahwa pada kelompok pemberian minyak esensial lavender dan jahe mempunyai $p=0,897$. Hal ini menunjukkan bahwa kedua minyak esensial lavender dan jahe mempunyai efek yang sama dalam penurunan intensitas nyeri menstruasi.

Pada penelitian ini ada perbedaan yang signifikan antara sebelum dengan sesudah pemberian minyak esensial baik lavender maupun jahe. Pada kelompok Lavender

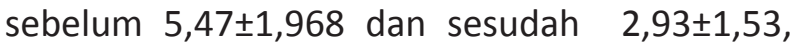
pada kelompok Jahe sebelum 5,40 $\pm 0,968$ dan sesudah 2,93 $\pm 1,43$. Berdasarkan uji statistik diketahui bahwa ada perbedaan yang signifikan terhadap penurunan intensitas nyeri sebelum dan sesudah diberikan minyak esensial lavender intensitas nyeri sebelum diberikan minyak esensial jahe dan sesudah diberikan minyak esensial jahe.

atau jahe (tabel 4). Efektivitas aromaterapi dalam mengurangi nyeri menstruasi disebabkan oleh cara kerja aromaterapi lebih dari satu yaitu memicu sistem limbik yang membantu dalam mengurangi rasa sakit dan pijatan perut menggunakan minyak esensial dapat meningkatkan sirkulasi darah yang berperan dalam pengurangan kejang yang menyebabkan nyeri. Kandungan utama penyusun minyak Lavender adalah linalool 26\%-49\% dan linalil asetat ${ }^{19}$, sifat farmakologi dari minyak Lavender dalam menimbulkan efek relaksasi dipengaruhi oleh linalool dan linalil asetat, efek farmakolgi menimbulkan relaksasi secara fisik maupun psikologis yang salah satunya memiliki sifat analgesik $^{19,20}$, dan menenangkan ${ }^{19,21}$, secara farmakologi minyak Lavender memiliki efek terapetik yang cukup luas yang mempengaruhi sistem saraf simpatis, parasimpatis dan sistim limbik.

Mekanisme kerja komponen aktif dalam Jahe seperti gingerol, gingerdion dan zingeron yaitu menghambat prostaglandin dengan cara menghambat enzim siklooksigenase dan lipoksigenase. Hal itu akan mengakibatkan penurunan leukotrien dan prostaglandin yang merupakan mediator radang. Efek tersebut sama dengan efek antiradang dari asam mefenamat dan ibuprofen yang merupakan golongan 
NSAID. ${ }^{12}$. Salah satu mekanisme terjadinya nyeri menstruasi adalah produksi prostaglandin di endometrium, yang merangsang terjadinya kontraksimiometrium ${ }^{22}$. Prostaglandin diproduksi oleh siklooksigenase dan lipoksigenase dari asam arakidonat. ${ }^{23}$ Pada seseorang yang menderita nyeri menstruasi konsentrasi prostaglandin $\mathrm{F}_{2} \alpha$ dan $E_{2} \alpha$ lebih tinggi. ${ }^{24}$ Obat-obat antiinflamasi golongan non-steroid seperti asam mefenamat menghambat sistesis prostaglandin melalui aktivitas siklooksigenase. Efek jahe pada nyeri menstruasi karena Senyawa gingerol dan gingerdion. Dengan mengontrol siklooksigenase dan aktivitas lipoxygenase ${ }^{25}$, senyawa ini menghambat leukotrien dan menginduksi efek anti inflamasi ${ }^{23}$, sehingga menekan produksi prostaglandin. ${ }^{26}$ Komponen Jahe yang tajam dan kuat secara khusus menghambat interleukin dalam makrofag ${ }^{27}$. Selain itu, salisilat dalam akar Jahe segar menghilangkan efek anti inflamasi, dan dapat digunakan untuk mengobati gangguan otot halus. ${ }^{28}$ Sehingga efektif pada nyeri menstruasi.

Beberapa penelitian dengan menggunakan minyak Lavender pada kelompok perlakuan dan plasebo untuk kelompok kontrol nyeri menstruasi menurun dari $82,38 \%$ menjadi $51,13 \%$ setelah pijat aromaterapi. ${ }^{13}$ Penelitian ini menunjukkan bahwa pijat aromaterapi efektif untuk mengurangi nyeri menstruasi dan memberikan efek yang lebih tinggi untuk pengurangan nyeri dibandingkan hanya dengan plasebo. Penelitian dengan menggunakan minyak Lavender yang dihirup terhadap nyeri menstruasi dan jumlah perdarahan selama menstruasi. ${ }^{29}$ Didapatkan bahwa gejala nyeri menstruasi secara signifikan menurun pada kelompok lavender dibanding kelompok plasebo $(p<0,001)$. Penelitian ini menunjukkan bahwa lavender secara inhalasi efektif untuk mengurangi gejala dan tingkat nyeri menstruasi. Penelitian pada kelompok perlakuan diberikan campuran beberapa minyak antara lain clary sage, marjoram, kayu manis, jahe dan geranium yang dilarutkan dalam minyak almond dengan konsentrasi akhir 5\% sedangkan kelompok kontrol diberikan acetaminophen menunjukkan hasil bahwa penurunan nyeri menstruasi secara signifikan lebih tinggi pada kelompok perlakuan dibandingkan kelompok acetaminophen. ${ }^{14}$

Berdasarkan penelitian dengan membandingkan asam mefenamat dan jahe dalam penanganan nyeri menstruasi primer, Pada kelompok asam mefenamat diberikan 250 mg kapsul setiap 8 jam, dan kelompok Jahe diberikan 250 mg kapsul setiap 6 jam dari onset menstruasi sampai nyeri berlangsung 2 siklus. Hasil penelitian menyatakan Jahe sama efektifnya dengan asam mefenamat untuk nyeri menstruasi primer. Jahe tidak memiliki efek samping dan merupakan pengobatan alternatif untuk nyeri menstruasi. ${ }^{30}$

Dari penelitian ini, Pada tabel Berdasarkan tabel 4 menggunakan Uji Mann Withney bahwa pada kelompok pemberian minyak esensial lavender dan jahe dengan $p=0,897$. Hal ini menunjukkan bahwa kedua minyak esensial lavender dan jahe mempunyai efek yang sama dalam penurunan intensitas nyeri menstruasi.

\section{KESIMPULAN DAN SARAN}

Intensitas nyeri sebelum diberikan minyak esensial lavender rata-rata 5,47 (nyeri sedang) dan sesudah diberikan rata-rata 2,93 (nyeri ringan). Intensitas nyeri sebelum diberikan minyak esensial jahe rata-rata 5,40 (nyeri sedang) dan sesudah diberikan rata-rata 2,93 (nyeri ringan). Minyak esensial lavender dan minyak esensial jahe sama-sama efektif dalam menurunkan intensitas nyeri menstruasi.

\section{Referensi}

1. Bobak, L. (2004). Buku Ajar Keperawatan Maternitas. Jakarta: EGC.

2. Harel, Z. (2006). Mini-Review Dysmenorrhea in Adolescents and Young Adults: Etiology and Management. Journal Pediatric Adolescent Gynecology.

3. Banikarim, C., Chacko,M.R., Kelder, S.H. (2000). Prevalence and Impact of Dysmenorrhea on 
Hispanic Female Adolescents. Arch Pediatr Adolesc Med.,154:1226-1229.

4. French, L. (2005). Dysmenorrhea. American Academy for Family Phisicians, 71(2), 285-291.

5. Lakshmi, A.P.M., Saraswathi I., Saravanan A., Ramamchandran C. (2011). Prevalence of Premenstrual Syndrome and Dysmenorrhoea among Female Medical Students and its Association with College Absenteeism. International Journal of Biological and Medical Research.

6. Zhou, H.G., Yang, Z.W. (2010). Prevalence of Dysmenorrhoea in Female Students in a Chinese University: A Prospective Study. Health Journal.

7. Mahmudiono, T. (2011). Fiber, PUFA and Calcium Intake is Associated With The Degree of Primary Dysmenorrhea In Adolescent Girl Surabaya, Indonesia. Journal of Obstretics and Gynecology.

8. Dawood, M.Y. (2006). Primary Dysmenorrhea Advances In Pathogenesis and Management. Journal Obstetric and Gynecologists. Vol. 108, No 2, August. Published by Lippincott williams \& Wilkins. ISSN 0029-7844/06.

9. Proctor, M., Farquhar, C., (2006). Clinical Review. Diagnosis and Management of Dysmenorrhea. Volume 332. BMJ.

10. Koensoemardiyah. (2009). A-Z Aromaterapi untuk Kesehatan, Kebugaran dan Kecantikan. Yogyakarta: Lily publisher Andi Offset.

11. Al-Anwar. (2003). The Good Scent Journal (Lavender). The Good Scents Company 2444 Atlanta Road Smyrna, Georgia 30080-2000.

12. Ozgoli, G., Goli, M., Moattar, F. (2009). Comparison of Effects of Ginger, Mefenamic Acid, and Ibuprofen on Pain in Women with Primary Dysmenorrhea. The Journal of Alternative and Complementary Medicine.

13. Apay, S.E., Arslan, S., Akpinar, R.B., Celebioglu, A. (2012). Effect of Aromatherapy Massage on Dysmenorrhea in Turkish Students. The American Society for Pain Management Nursing.

14. Hur, M.H., Lee, M.S., Seong, K.Y., Lee, M.K. (2011). Aromatherapy Massage on the Abdomen for Alleviating Menstrual Pain in High School Girls: A Preliminary Controlled Clinical Study. Journal Complementary and Alternative Medicine.
15. American Academy of Child and Adolescent's Facts for Families. (2008). Stage of Adolescent Development.

16. The American Academy of Pediatric. (2006).

17. Wong, C.L., Lai, K.Y., Tse, H.M. (2011). Effects of SP6 acupressure on pain and menstrual distress in young women with Dysmenorrhea. Complementary Therapies in Clinical Practice.

18. Pilliteri. A. (2010). Maternal and Child Health Nursing. $6^{\text {th }}$ edition. Wolter Kluwer. New York

19. Price and Shirley. (2007). Aromatherapy for Health Proffesionals. Philadelphia: Elsevier Science.

20. McGuinness, Helen. (2007). Aromatherapy, Therapy Basics $2^{\text {nd }}$ edition. London: Hodder Arnold.

21. Cook, Neal. (2008). Aromatherapy: Reviewing Evidence for its Mechanism of Action and CNS Effect. British Journal of Neuroscience Nursing, 4(12),592-601.

22. Kim JK, Kim Y, Na KM, Surh YJ, Kim TY (2007) Gingerol prevents UVB-induced ROS production and COX2 expression in vitro and in vivo. Free Radic Res 41(5):603-614

23. Grzanna R, Lindmark L, Frondoza CG (2005) Gingeran herbal medicinal product with broad antiinflammatory actions. J Med Food 8(2):125-132

24. Ife J, Magowan B (2004) Clinical obstetrics and gynecology. WB Saunders, Edinburgh

25. Kim SO, Kundu JK, Shin YK, Park JH, Cho MH, Kim TY et al (2005) Gingerol inhibits COX-2 expression by blocking the activation of p38 MAP kinase and NF-jB in phorbol esterstimulated mouse skin. Oncogene 24(15):2558-2567

26. Rahnama P, Montazeri A, Huseini HF, Kianbakht S, Naseri M (2012) Effect of Zingiber officinale R. rhizomes (ginger) on painrelief in primary dysmenorrhea: a placebo randomized trial. BMC Complement Altern Med 12(1):92. doi:10.1186/1472-6882-12-92 21.

27. Nievergelt A, Marazzi J, Schoop R, Altman KH, Gertsch J (2011) Ginger phenylpropanoids inhibit IL-1b and prostanoid secretion and disrupt arachidonate-phospholipid remodeling by targeting phospholipases A2. J Immunol 187(8):4140-4150

28. Altman R, Marcussen K (2001) Effects of a ginger extract on knee pain in patients with osteoarthritis. Arthritis Rheum 44(11):2531-2538 
29. Dehkordi, Z.R., Baharanchi, F.S.H., Bekhradi, R. (2014). Effect of lavender inhalation on the symptoms of primary Dysmenorrhea and the amount of ${ }^{1}$ menstrual bleeding: A randomized clinical trial. Journal Complementary Therapies Medicines.
30. Shirvani, M.A dan Tabari, N.M. (2014). The Efeect of Mefenamic acid and ginger on pain relief in primary dysmenorrheal: a randomized clinical trial. Arch Gynecol Obstet. 